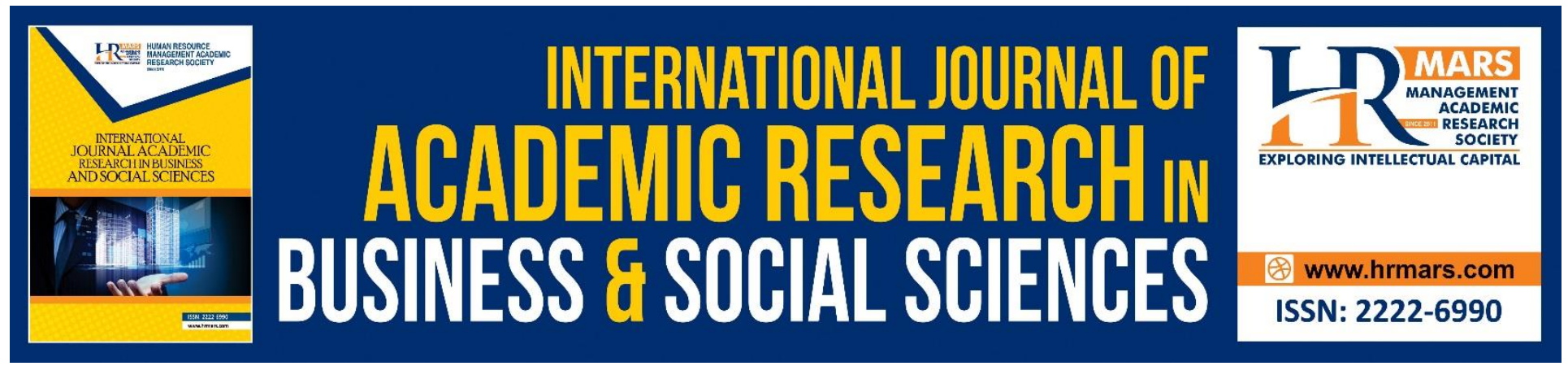

\title{
Indirect Relationship of Attachment, Immediacy, Interpersonal Needs and Interpersonal Attraction between Emotional Intelligence and Life Satisfaction: An Empirical Study of Malaysian Undergraduates
}

Kunnasunthary S Ramachandran, Hanina H. Hamsan, \& Azlina Mohd. Khir

To Link this Article: http://dx.doi.org/10.6007/IJARBSS/v10-i16/8309 DOI:10.6007/IJARBSS/v10-i16/8309

Received: 13 October 2020, Revised: 15 November 2020, Accepted: 10 December 2020

Published Online: 22 December 2020

In-Text Citation: (Ramachandran et al., 2020)

To Cite this Article: Ramachandran, K. S., Hamsan, H. H., \& Khir, A. M. (2020). Indirect Relationship of Attachment, Immediacy, Interpersonal Needs and Interpersonal Attraction between Emotional Intelligence and Life Satisfaction: An Empirical Study of Malaysian Undergraduates. International Journal of Academic Research in Business and Social Sciences, 10(16), 237-249.

\section{Copyright: (c) 2020 The Author(s)}

Published by Human Resource Management Academic Research Society (www.hrmars.com)

This article is published under the Creative Commons Attribution (CC BY 4.0) license. Anyone may reproduce, distribute, translate and create derivative works of this article (for both commercial and non-commercial purposes), subject to full attribution to the original publication and authors. The full terms of this license may be seen

at: http://creativecommons.org/licences/by/4.0/legalcode

Special Issue: Youth and Community Wellbeing: Issues, Challenges and Opportunities for Empowerment V2, 2020, Pg. 237 - 249 


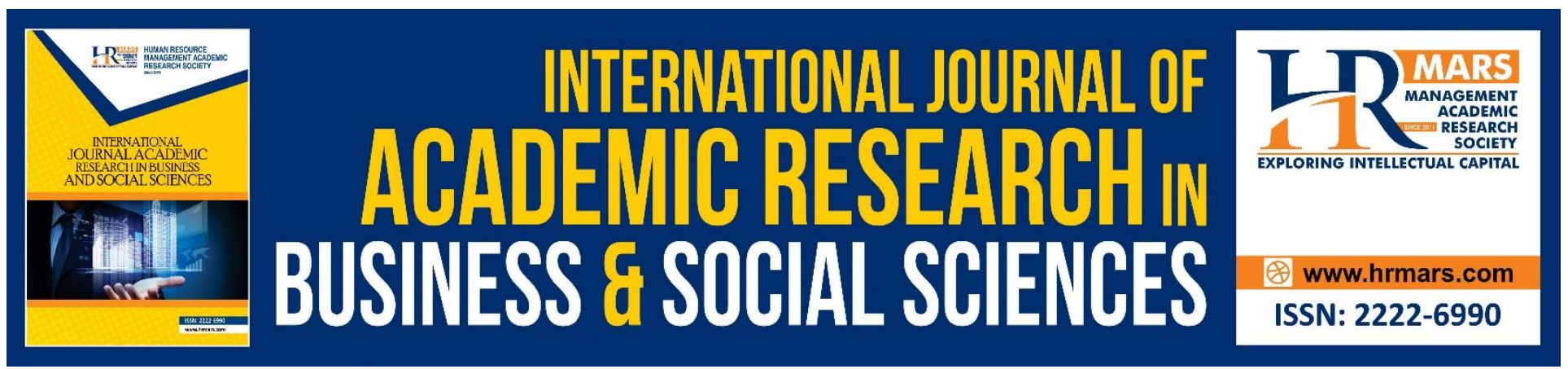

\title{
Indirect Relationship of Attachment, Immediacy, Interpersonal Needs and Interpersonal Attraction between Emotional Intelligence and Life Satisfaction: An Empirical Study of Malaysian Undergraduates
}

\author{
Kunnasunthary S Ramachandran², Hanina H. Hamsan ${ }^{1,2^{*}}$ \& Azlina \\ Mohd. Khir ${ }^{2}$ \\ ${ }^{2}$ Faculty of Human Ecology Manusia, Universiti Putra Malaysia, 43400 UPM Serdang, Selangor Darul \\ Ehsan, Malaysia, ${ }^{1}$ Institute for Social Science Studies, Universiti Putra Malaysia, 43400 UPM \\ Serdang, Selangor Darul Ehsan, Malaysia \\ Email: tanuja_ashra@yahoo.com,hanina@upm.edu.my,m_azlina@upm.edu.my
}

\begin{abstract}
Life satisfaction is a global evaluation can be determined by a strong capability of thoughts and feeling called emotional intelligence. At the same time, these two elements indirectly effect by certain psychosocial attributes such as attachment relationship of lecturers, attachment relationship of peers, immediacy behaviour of lecturers, interpersonal needs and interpersonal attraction of peers. Therefore, aim of this study proposed that determine the indirect relationship of attachment, immediacy, interpersonal needs and interpersonal attraction between emotional intelligence and life satisfaction among 600 undergraduate students in Klang Valley area. The two theories applied in this study are, PERMA model and Emotional Intelligence The results support the hypothesis of the study and revealed that attachment relationship of lecturer's, immediacy behaviour of lecturer's and interpersonal needs of students significantly played a mediator role based on Hayes Mediation Analysis Bootstrapping. It means there was an indirect and direct relationship between variables. Students, who had positive psychosocial attribution, had high level of emotional intelligence and life satisfaction.
\end{abstract}

Keywords: Emotional Intelligence, Life Satisfaction, Attachment Relationship, Immediacy Behaviour, Interpersonal Needs, Interpersonal Attraction.

\section{Introduction}

Higher education institutions for students played an important role here to identify the factor of life dissatisfaction. Most of student first task in university life is, living away from family. Therefore, this is the main reason why university management need to care of students' life satisfaction. Students 
who with positive perception and thoughts, show satisfaction in life by good relationship with university community (lecturers and peers). In the other way, student's who lack of satisfaction identified as has negative perspective and feeling towards university community. Hence, life satisfaction mainly influence by students emotion and intellectual as declared as emotional intelligence.

Emotional intelligence is essential tool in indicating life satisfaction (Marzuki, Zubir@Salim and Abd Rani, 2018). Helliwell, (2018) stated in world happiness report that 200 million students in university suffering by mental health problem in aged between 18 until 26. Hence, mental health apparently related with emotional intelligence is a big key feature to identify student's satisfaction level in campus. Student's who had de-motivated thoughts lead to dissatisfaction level in learning process. Indirectly other factors also influences in this matter (Wongpakaran et al., 2016; Mutegi \& Kyalo, 2014).

A lot of people disputed that is more essential to increase the life satisfaction of people for whom it is less than of those for whom it's already high. For this, an individual require to build emotional buoyancy that responsible for his or her life satisfaction especially who was functioning as young adult (Saarni, 1999). Based on Thackray (2017) in World Health Organization Report 23\% young adult affect by mental health rather than physical ill health. However continuous mental health might affect physical health also in a person indirectly.

According to Grewal, Brackett and Salovey (2006) mental health is important for satisfied life. The cause of mental health problem is poor emotional intelligence level among young adult. This is partly because young adult mostly learning in higher facing an unhealthy environment surrounding them. Therefore, the emotional intelligence level to need established among students who perusing tertiary education in university or college for design life style in learning to set.

Consequently based on Malaysian Well-Being Report (Yogeesvaran, 2013) many factors involving in individual life satisfaction which are working life, education, income, leisure, culture, heart, environment, family, communication, public safety, transport, social participation, family and housing. This life satisfaction in education filed requires identifying by social psychology factor which is emotional intelligence among Malaysian students in higher education institutions. Despite, very lack of study was done in Malaysia regarding emotional intelligence with life satisfaction or in academic setting.

Therefore, in this research emotional intelligence was chosen as predictor due to the fact that unable to control and manage oneself and others directly force into dissatisfaction environment among young adult in university life. As noted previously, prior research had investigated emotional intelligence as a general approach. It looked into the pleasant and unpleasant experiences, emotions, feelings and thoughts of oneself and others in academic achievement of students. However, this present study looked at the students' level emotional intelligence which intended to identify the level of ability to understand and influence other's towards their life satisfaction in campus setting. 
Many predictors were directly (input) and indirectly (throughout) affect student life satisfaction in campus. The relationship of different predictors with students life satisfaction have been studied by researchers (Kim, 2004; Murphy, 2006; Nabavi et al., 2014; Paydar, Jamalabadi, \& Far, 2014). University life totally difference from school life by academically, socially and physically. Hereby, peer's and lecturer's played important role in a student's university life. In order, peer's and lecturer's attachment relationship influenced student's learning life especially in life aspect (Veenhoven, 2015). Thus, current study applied attachment relationship of lecturer and attachment relationship of peer as one of the mediator between emotional intelligence and life satisfaction.

When a student capability to think and observe an issue in positive way, create a positive perception on lecturer's verbal and nonverbal attributes which increase satisfaction level among that students (Sabri \& Falahati, 2012). Hence, prior study employed immediacy behaviour of lecturer as a second mediator in this study. Next, interpersonal attraction of peer's also has indirect impact on life satisfaction. A person who attract to others personally, make the person to interact more convenient and comfortable (Adnan \& Mavi, 2015). Emotional cognitive thinking actually influences a person attraction on others. A good emotion and positive attraction directly and indirectly increase life satisfaction among undergraduates.

Last but not least, interpersonal needs identify as another mediator in study between students life satisfaction. Interpersonal needs defined by scholars that, an individual inclusion, affection and control personally well established mean their requirements in life accomplished (Cheng, Treglown, Green, P.Chapman, N.Kornilaki, 2016; Gander, Proyer, and Ruch, 2016). By doing this, satisfaction level increases when an individual needs fulfilment. However if a person feels emotionally bad, unable to fulfil his or her needs, partially tends to dissatisfaction level of life. Thus, this study concluded to identify how indirectly interpersonal needs played as throughout variables between emotional intelligence and life satisfaction.

The purpose of this study is to determine the mediating effect of attachment relationship of peers and lecturers, immediacy behaviour of lecturers, interpersonal needs of students and interpersonal attraction of peers on the relationship emotional intelligence and life satisfaction among undergraduate students, to enhance university administration to find out the factors directly and indirectly effect students life quality in campus.

\section{Theoretical Framework}

In this study, emotional intelligence model theory (Mayer and Salovey, 1997) was applied for independent variable (emotional intelligence), while PERMA model employed for dependent variable (life satisfaction). The emotional intelligence model proposed ability to perceive, revealed, maintain and monitor emotion which exist in an individual life. At the same time, a person perception towards other's directly influenced by emotional and cognitive. Regard on this, emotional intelligence model will be platform for emotional intelligence correlated directly to psychosocial behaviour such as attachment relationship, immediacy behaviour, interpersonal needs and interpersonal attraction in this study. 
On the other word, PERMA model (Seligman, 2010) was used in this study to express which mediator variable indirectly effect on life satisfaction and how the effects can improve in students living style. Therefore PERMA divided into five elements that are 'Positive emotion' as emotional intelligence, 'Engagement' as immediacy behaviour, 'Relationship' as attachment, 'Meaning' as interpersonal attraction and 'Achievement' as interpersonal needs.

Based on theoretical development, the following hypotheses were proposed:

H1: Attachment relationship of lecturer's mediates significantly the relationships between emotional intelligence with life satisfaction.

H2: Attachment relationship of peer's mediates significantly the relationships between emotional intelligence with life satisfaction.

H3: Immediacy behaviour of lecturer's mediates significantly the relationships between emotional intelligence with life satisfaction.

H4: Interpersonal needs of students mediate significantly the relationships between emotional intelligence with life satisfaction

H5: Interpersonal attraction of peer's mediates significantly the relationships between emotional intelligence with life satisfaction

\section{Method}

\section{Research Instruments}

A quantitative method takes over in this study. A survey questionnaire based on previous study instrument was applied in this study. As for life satisfaction applied Alfonso, Allison, Rader and Gorman (1996) instrument called as Extended Life Satisfaction Scale ( $r=0.980)$, as well as for emotional intelligence employed Schutte et al., (1998) Emotional Scale (SEIS) ( $r=0.837$ ). Meanwhile the mediator variables attachment relationship applied Inventory of Parent and Peer Attachment (IPPA) Scale of Bowlby and Ainsworth, (1969) ( $r=0.965)$, immediacy behaviour utilized 'Christophel' (1990) Immediacy Behaviour Scale ( $r=0.855)$, interpersonal attraction used McCroskey, Daly and Sorensen (1976) Interpersonal Attraction scale ( $r=0.921)$ and interpersonal needs applied Firo BSchutz Scale (Schutz, 1978) ( $r=0.798)$.

\section{Data Collection Technique}

The data collection method employed in this quantitative study was survey design. The survey data were collected face-to-face by the researcher.

\section{Sample}

The location of this study is Klang Valley area because the largest population of undergraduates which comprised of Kuala Lumpur as capital of Malaysia and its adjoining cities from Selangor. Therefore, 600 undergraduate students were selected in this study from Klang Valley Universities. Target sample 
represents the generalized population and this study applied multistage cluster sampling to choose a sample. These universities divided into two groups called as IPTA (public higher learning institutions) and IPTS (private higher learning institutions). This research focused two universities from each group and two faculty randomly selected in each universities.

The universities selected for this study are Universiti Malaya (Faculty of Law and Faculty of Medicine), Universiti Putra Malaysia (Faculty of Modern Language and Communication and Faculty of Human Ecology), Universiti Tenaga Nasional (Faculty of Engineering and Faculty of Management) and Universiti Kuala Lumpur (Faculty of Computer Science and Faculty of Bussiness). Then, one class from each faculty was randomly selected as respondents of this study.

\section{Analysis}

This study employed Hayes Meditation Analysis bootstrapping (Hayes and Preacher, 2014) in identify the mediating variable effect between independent variable and dependent variable. Based on Figure 1 , emotional intelligence as $X$ directly influenced life satisfaction as $Y$, mediated by $M 1$ (attachment relationship of lecturer's), M2 (attachment relationship of peer's), M3(immediacy behaviour of lecturer's), M4(interpersonal need's) and M5(interpersonal attraction of peer's). Hence, the model was tested for serial multiple mediation (SMM) through turning the mediator arrangement to find how often mediator impact on each other. An unique mediation effect means a multiple mediation model make sure there was throughout effect and maybe control collinearly between independent variable and indirect effects. Therefore, this study applied Hayes Bootstrapping because of multiple mediator consider as new contribution of the study.

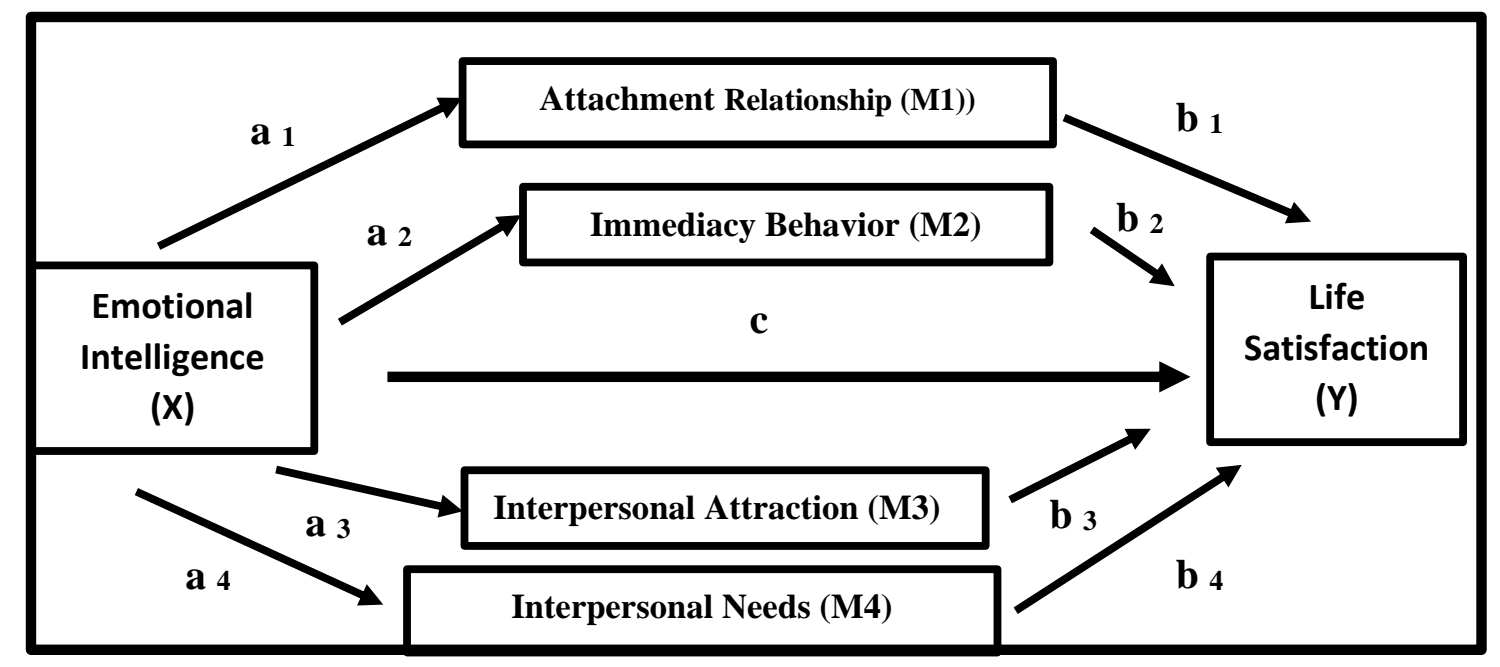

Figure 1 : Multiple Mediation Model

\section{Results}

Mediation analyses carry out in accordance with the method approached by (Hayes, 2017). As mentioned in method section, this mediation effects analysis need that four primer conditions to be achieve for a variable to be declared as a mediator. It means emotional intelligence required to be significantly correlated with life satisfaction, then it followed by attachment relationship of lecturer's, 
attachment relationship of peer's, immediacy behaviour of lecturer's, interpersonal need's and interpersonal attraction of peer's significantly correlated with life satisfaction. As last step the impact of emotional intelligence on life satisfaction identify whether increase or decrease based on mediators effects.

Thus, Figure 1 showed the result of mediating relationship model between independent variable (emotional intelligence) and dependent variable (life satisfaction). This diagram illustrated that emotional intelligence significantly associated with life satisfaction ( $b=0.03, p<0.05$ ) (c path), as total effect when there was no other predictor in the model. Despite, this effect declined to $b$ $=0.0073, p<0.05$ when the mediator was contributed $\quad\left(c^{\prime}\right.$ path). To identify the significant effect, $Z$ score applied for the total indirect effect called as path ' $b$ ' which showed the null hypothesis of the study whether reject or accept based on $p<0.05$. Hereby this study showed mediating variables' indirect effect model approximately as below.

Model 1: Mediating effect of attachment relationship lecturers on the relationship emotional intelligence and life satisfaction among undergraduate students

Therefore mediating effect through attachment relationship of lecturer's $(b=.256, Z=0.182, p=0.04)$ was significant based on Figure 2. The true indirect effect of attachment relationship of lecturer's was estimated to lie between lower 0.278 and upper 0.4656 with 95 percent confidence as showed in Table 1. There was no zero in the 95 percent confidence interval, the results of findings claimed that the indirect effect by attachment relationship of lecturer's was significantly different from zero at $p$ $<0.05$ ( 2 tailed) and declared the specific indirect effect of variable presence in the relationship between emotional intelligence and life satisfaction. The hypothesis of study was supported in this study based on the findings.

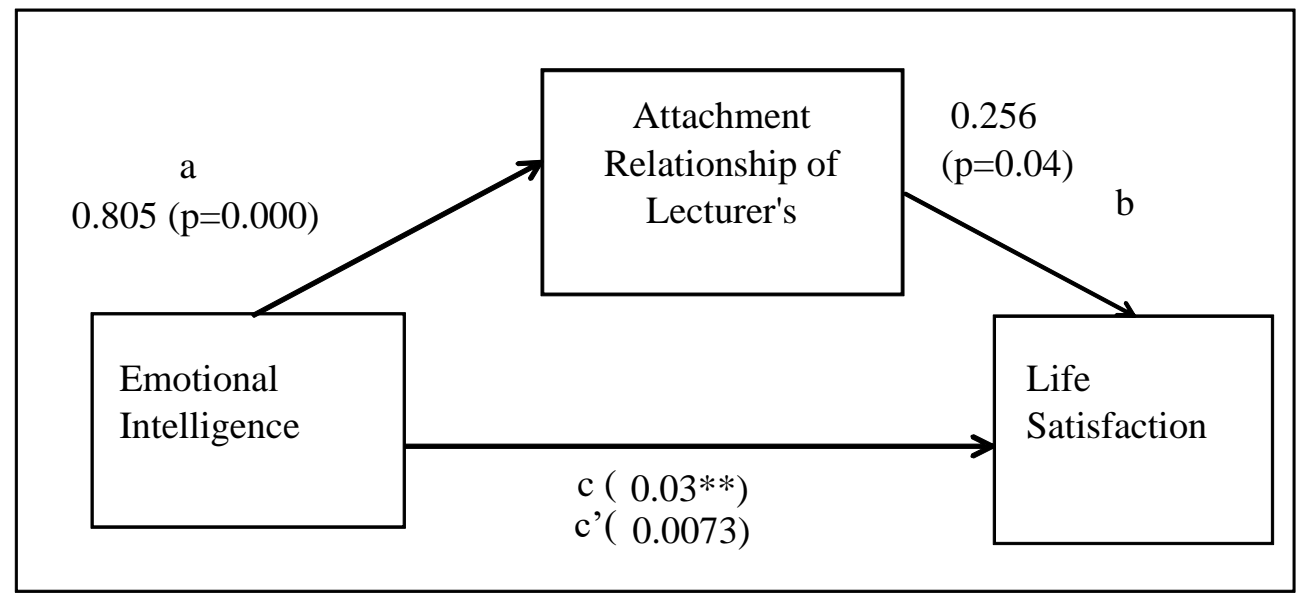

Figure 2: Model (1) of Relationship between Variables Investigated 
Model 2: Mediating effect of attachment relationship of peers on the relationship emotional intelligence and life satisfaction among undergraduate students

There is no mediating effect by attachment relationship of peer's ( $b=.124, Z=0.88, p=0.37)$ based on Figure 3. Table 1 showed 95 percent confidence with lower .1947 and upper .3996 of attachment relationship of peer's. This result revealed that attachment relationship of peer's was not significantly played mediator role between emotional intelligence and life satisfaction as well as the hypothesis fail to support in this study.

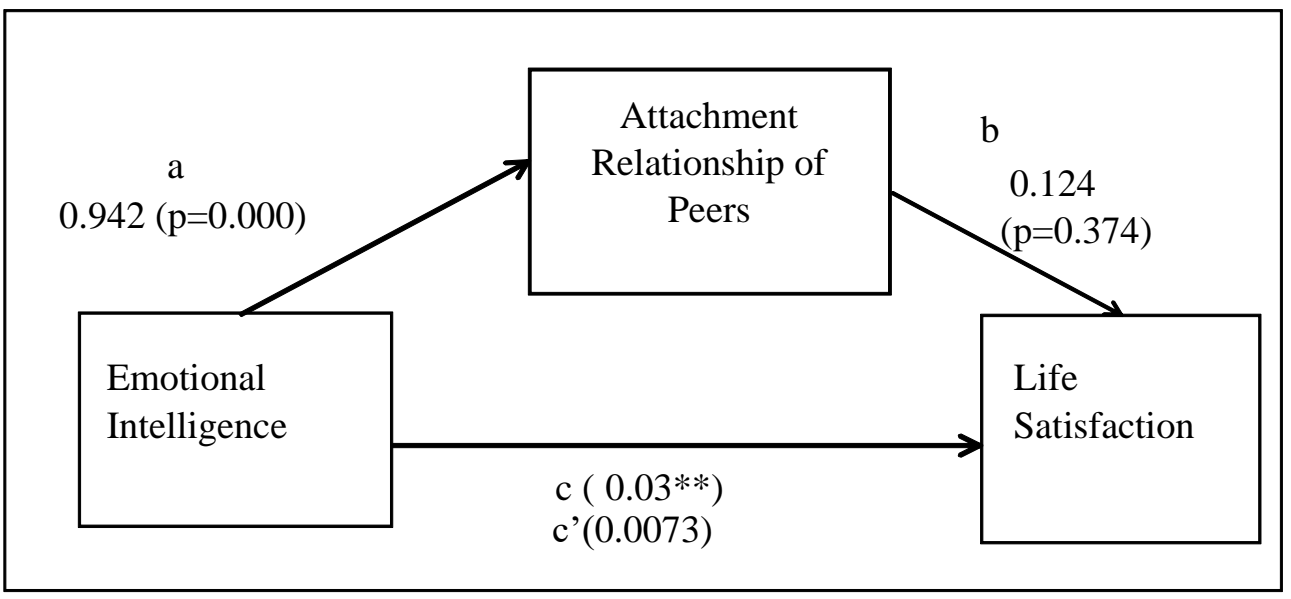

Figure 3: Model (2) of Relationship between Variables Investigated

Model 3: Mediating effect of immediacy behavior of lecturers on the relationship emotional intelligence and life satisfaction among undergraduate students

Hence mediating effect via immediacy behaviour of lecturer's ( $b=.257, Z=0.090, p=0.01$ ) was significant based on Figure 4. The true indirect effect of immediacy behaviour was estimated to lie between lower .0213 and upper .3858 with 95 percent confidence as showed in Table 1 . There was no zero in the 95 percent confidence interval, the result findings mentioned that there was an indirect effect through immediacy behaviour of lecturer's was significant different from zero at $p<0.05$ ( 2 tailed) and revealed the specific indirect effect of immediacy behaviour of lecturer's in the relationship between emotional intelligence and life satisfaction. The hypothesis of study was supported in this study based on the findings. 


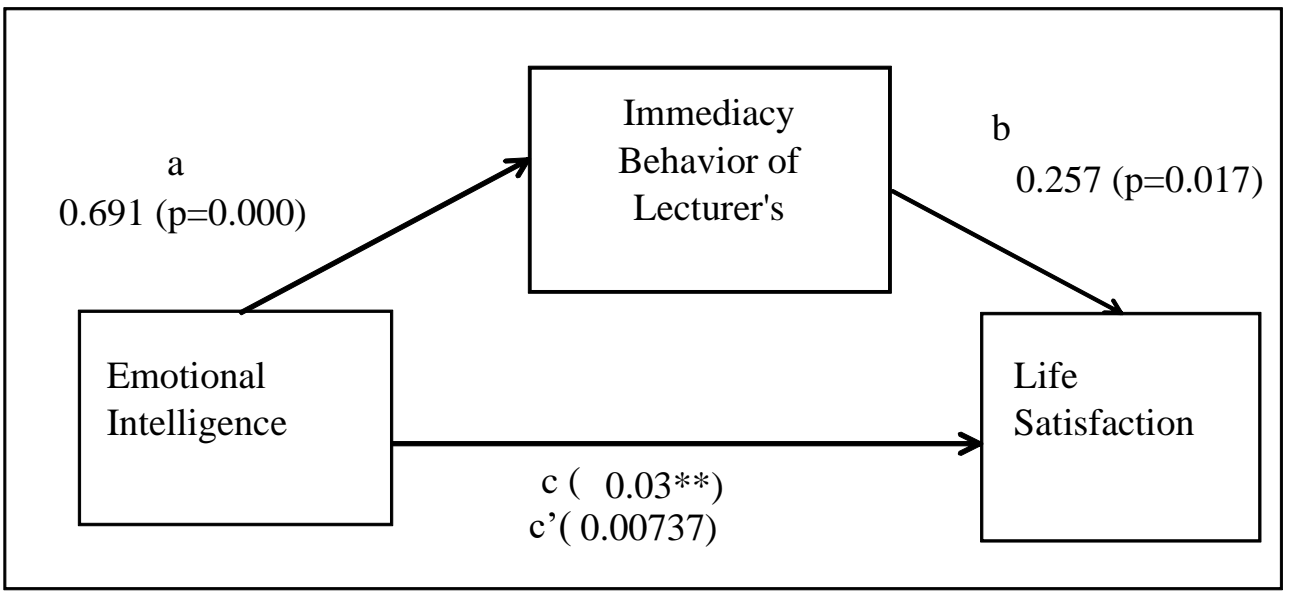

Figure 4: Model (3) of Relationship between Variables Investigated

Model 4: Mediating effect of interpersonal needs of students on the relationship emotional intelligence and life satisfaction among undergraduate students

Thus indirect effect by interpersonal needs of students $(b=.384, z=1.54, p=0.03$ ) was significant showed in Figure 5. The true mediating effect of interpersonal needs of students was estimated to lie between lower .0693 and upper .4138 with 95 percent confidence as shown in Table 1. There was no zero in the 95 percent confidence interval, the findings suggested that there was indirect effect via interpersonal needs of students was significantly different from zero at $p<0.05$ ( 2 tailed) and stated as interpersonal needs of students presence as mediator between emotional intelligence and life satisfaction. The hypothesis of study was supported in this study based on the findings.

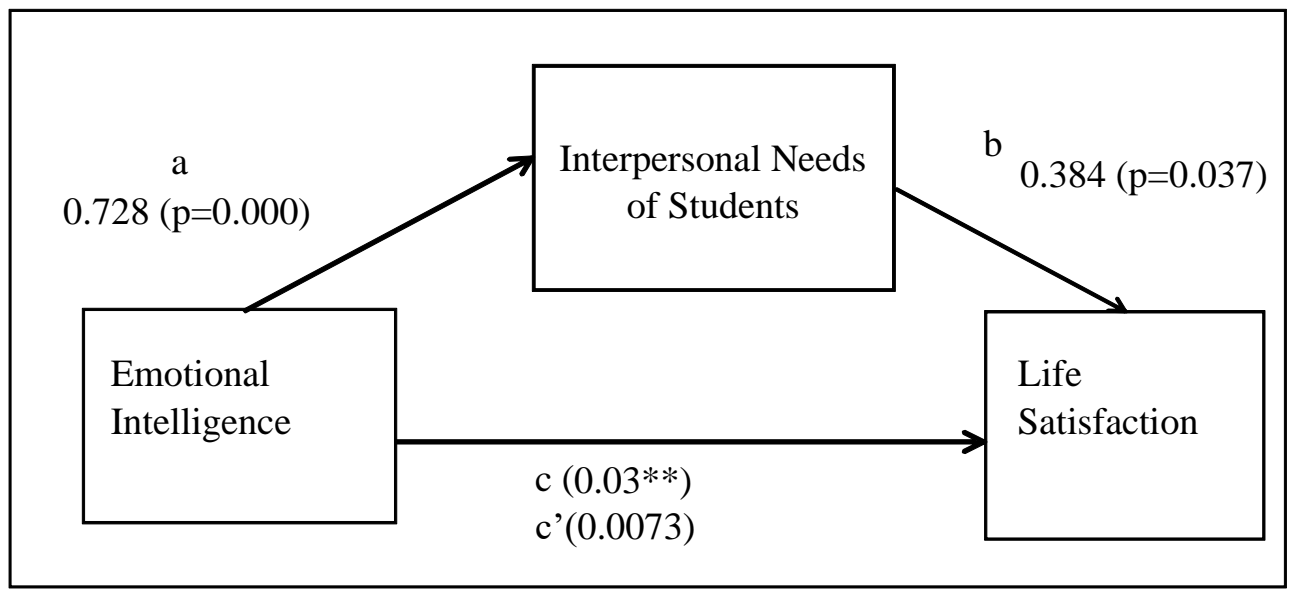

Figure 5: Model (5) of Relationship between Variables Investigated 
Model 5: Mediating effect of interpersonal attraction of peers on the relationship emotional intelligence and life satisfaction among undergraduate students

Therefore, interpersonal attraction of peer's significantly did not have indirect effect between independent variable and dependent variable $(b=.168, Z=0.14, p=0.11)$ based on Figure 6 . The 95 percent confidence with lower -.3785 and upper .3561 was showed in Table 1 . The findings of result declared that interpersonal attraction of peer's not as good as mediator between emotional intelligence and life satisfaction in campus setting among undergraduates. The hypothesis was study fail to support regarding the result of findings.

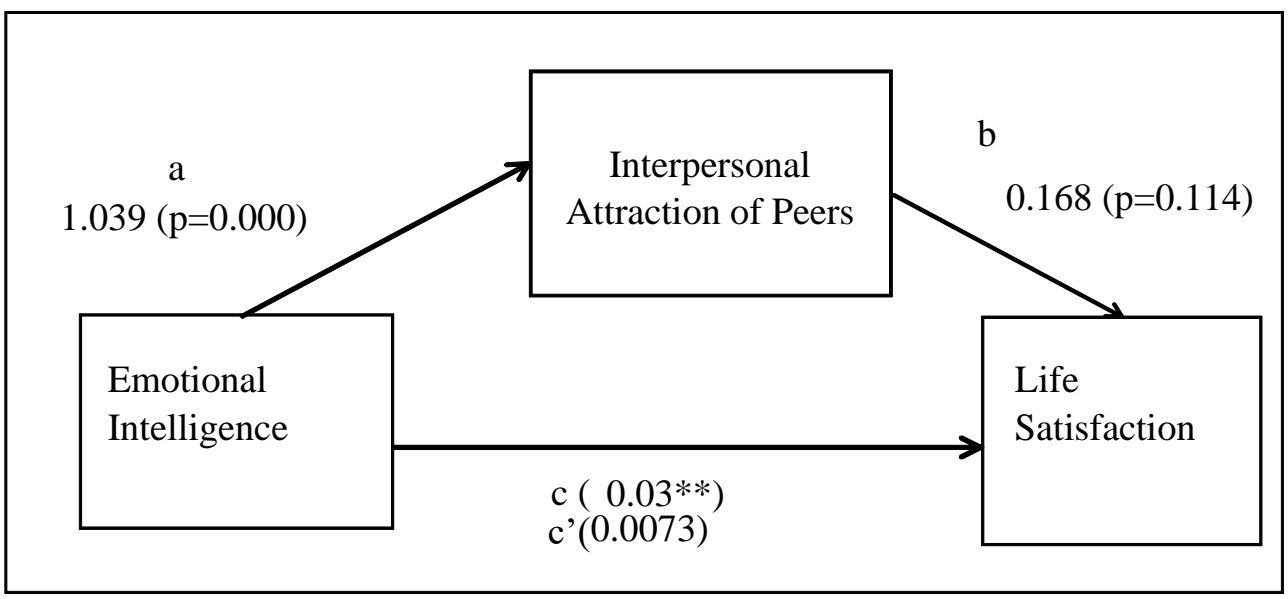

Figure 6: Model (5) of Relationship between Variables Investigated

\section{Discussions}

This section explores a meditational model for the link among attachment relationship of lecturer's, attachment relationship of peer's, immediacy behaviour of lecturer's, interpersonal need's and interpersonal attraction of peer's, emotional intelligence and life satisfaction. Figure 3 shows the whole mediator variables associated each other to determine the significant indirect effect between emotional intelligence and life satisfaction. The findings in Table 1 explained that only attachment relationship of lecturer's, immediacy behaviour of lecturer's and interpersonal needs' have indirect effect between emotional intelligence and life satisfaction, while attachment relationship of peer's and interpersonal attraction of peer's did not have any significant relationship as mediator between independent and dependent variable.

Based on the result, hypothesis of study on emotional intelligence and attachment relationship of lecturer accept and support past study of Sharnowski (2009) that without attachment bonding between lecturer-student, there will be difficulty in quality academic adjustment and approachability among students. Students strongly attach to their lecturer as a caretaker, influence students' adjustment and adaptation in campus life. While, hypothesis regarding mediating effect of immediacy behavior on life satisfaction and emotional intelligence also take into account because similar with Christophel (1990) study. Besides that, mediating result of interpersonal needs between 
emotional intelligence and life satisfaction also support previous partial similar study of Wongpakaran et al (2016).

Hence, lecturer attachment relationship and emotional intelligence is an essential tool among undergraduates for a well satisfaction level at campus (Cheng et al., 2016). Lecturer attachment relationship successfully intent to add the affect of intervening process in the relationship between emotional intelligence and life satisfaction as it is a corresponding variable in the model. Besides that, immediacy behaviour of lecturer's also played a significant mediator role between emotional intelligence and life satisfaction based on result. Respondents who high level of emotional intelligence more likely to adopt to their lecturer immediacy cues, whereby indirectly increase satisfaction level among students (Gander et al., 2016). Continuously, interpersonal needs of students' also very essential elements in indirectly impact on student's emotional intelligence and life satisfaction. By positive emotional intelligence among students, ability to observe and control their interpersonal needs which lead to a comfortable, convenient and delight surrounding at campus (Grewal et al., 2006).

In terms of theory, these findings of study support Emotional Intelligence theory that emotional intelligence had direct relation with attachment relationship of lecturer, attachment relationship of peer's, immediacy behaviour of lecturer's, interpersonal attraction and interpersonal needs. Meanwhile, PERMA model proved that majority of its' elements significantly represented mediator variable such as attachment relationship, immediacy behaviour, interpersonal needs and only interpersonal attraction not contribute to life satisfaction (Seligman, 2010). Therefore, the result engaged partially with theoretical framework and also supported most of hypothesis of the day $(\mathrm{H} 1$, $\mathrm{H} 3$, and H4). Hereby the findings partially support means, mainly lecturers played more important role in students' perspective emotionally and cognitively towards life satisfaction than peers.

Therefore, attachment relationship and immediacy behaviour of lecturers successfully contribute as mediator in this study, which means lecturer social behaviour need to take into account for a great life satisfaction level among undergraduates (Christophel, 1990). Finally, the findings reviewed in this section were not capable to be compared directly with prior studies, indicating there was lack of literature which had addressed similar issue. Thus, this finding categorized as new contribution in student's life satisfaction at campus setting.

\section{Conclusion}

The summary was drawn from the outcome of the study. The feedback of study briefly showed that the undergraduate students for the prior study benefitted confirmly in term of psychosocial and educational development. The outcome showed emotionally, cognitively and motivationally the students have benefitted, followed with satisfaction of life. As indicating that student's perception on attachment relationship of lecturer's, immediacy behaviour and interpersonal needs positively increase student's life satisfaction by emotional intelligence in manner way.

In Malaysia, as there are very few students concerning the life satisfaction among undergraduates, it is essential to take a preliminary step in exploring and predicting undergraduate students' emotional 
intelligence and their level of life satisfaction. In addition, it can enhance to establish our understanding of the factor predicting life satisfaction and prior research will be a new contribution to the content of knowledge. The research findings in recommendation on particular solution of emotional intelligence, attachment relationship, immediacy behavior, interpersonal needs and interpersonal attraction were recognized. Steps such as controlling, managing, utilizing, perceiving and so on enable the undergraduate to manage their well-being of life.

Therefore, it can be concluded that this mediator variables significantly contribute to life satisfaction and emotional intelligence by indirect effect among undergraduate students in learning process. Another important element that student more concern on his or her lecturer as a role model for better living style at campus.

\section{Acknowledgment}

Deeply acknowledge those who support, assist and guide during overall the study. Without this consideration and cooperation, this study might not have been possible.

\section{References}

Adnan, H. M., \& Mavi, S. R. (2015). Facebook satisfaction, life satisfaction: Malaysian undergraduate experience. Jurnal Komunikasi: Malaysian Journal of Communication, 31(2), 649-671. Retrieved from https://www.scopus.com/inward/record.uri?eid=2s2.084983200826\&partnerID=40\&md5=fa8c891c86e9fbd43356c8ebe62d9463

Alfonso, V. C., Allison, D. B., Rader, D. E., \& Gorman, B. S. (1996). The extended satisfaction with life scale: Development and psychometric properties. Social Indicators Research, 38(3), 275-301.

Bowlby, J., \& Ainsworth, M. (1969). Attachment theory. Human Evolution, 4. https://doi.org/10.1080/14616730701711540

Christophel, D. M. (1990). The relationships among teacher immediacy behaviors, student motivation, and learning. Communication Education. https://doi.org/10.1080/03634529009378813.

Francis-sharnowski, M. A. (2009). Relationships Among Parent Attachment, Ego Identity, Life Satisfaction, And Relationship Closeness For Male And Female College Students by Submitted to the Graduate School of Wayne State University Detroit, Michigan in partial fulfillment of the requi. Education Psychology. Retrieved from http://elibrary.wayne.edu/record=3616840.

Gander, F., Proyer, R. T., \& Ruch, W. (2016). Positive psychology interventions addressing pleasure, engagement, meaning, positive relationships, and accomplishment increase wellbeing and ameliorate depressive symptoms: A randomized, placebo-controlled online study. Frontiers in Psychology, 7(MAY), 1-12. https://doi.org/10.3389/fpsyg.2016.00686

Grewal, D., Brackett, M., \& Salovey, P. (2006). Emotional Intelligence and the Self-Regulation of Affect. Emotion Regulation in Couples and Families: Pathways to Dysfunction and Health. https://doi.org/http://dx.doi.org/10.1037/11468-002

Hayes, A. F., \& Preacher, K. J. (2014). Statistical mediation analysis with a multicategorical independent variable. British Journal of Mathematical and Statistical Psychology, 67(3), 451470. https://doi.org/10.1111/bmsp.12028 
Hayes. (2017). Hayes, Andrew F.. Methodology In The Social Sciences : Introduction to Mediation, Moderation, and Conditional Process Analysis : A Regression-Based Approach. New York, US: The Guilford Press, 2013. ProQuest ebrary. Web. 4 April 2017. Copyright (C) 2013.

John, F., Helliwell, R. L. (2018). World Happiness Report 2018. Global Happiness Policy Report 2018. Retrieved from http://worldhappiness.report/

Kim, R. K. (2004). The Relationship Between Student Satisfaction and Emotional Intelligence Among Undergraduate Students Enrolled In Nursing Programs. Retrieved from https://www.researchgate.net/.../254725553_The_relationship_between_student_satisfactio $\mathrm{n}$.

Mayer, J. D., \& Salovey, P. (1997). What is emotional intelligence? Emotional Development and Emotional Intelligence: Educational Implications.

Mutegi, J. M., \& Kyalo, P. M. (2014). Origins of Human-Wildlife Conflicts in Meru District, 1920-1939. International Journal of Academic Research in Public Policy and Governace, 1(1), 60-75.

Murphy, K. T. (2006). The relationship between emotional intelligence and satisfaction with life after controlling for self- esteem, depression, and locus of control among community college students. Graduate Theses and Dissertations. Retrieved from http:://scholarcommons.usf.edu/etd/2640.

McCroskey, J. C., Daly, J. A., \& Sorensen, G. (1976). Personality Correlates of Communication Apprehension: a Research Note. Human Communication Research, 2(4), 376-380. https://doi.org/10.1111/j.1468-2958.1976.tb00498.

Paydar, H., Jamalabadi, H. R. R., \& Far, N. Y. (2014). The Research Relationship between the Operation Cycle and the Criteria ROS and ROA. International Journal of Academic Research in Public Policy and Governace, 1(1), 41-49.

Sabri, M., \& Falahati, L. (2012). Estimating a Model of Subjective Financial Well-Being among College Students. International Journal of Humanities and Social Science, 2(18), 191-199.

Saarni, C. (1999). A Skill-Based Model of Emotional Competence: A Developmental Perspective. https://doi.org/ED419696

Schutte, N. S., Malouff, J. M., Hall, L. E., Haggerty, D. J., Cooper, J. T., Golden, C. J., \& Dornheim, L. (1998). Development and validation of a measure of emotional intelligence. Personality and Indiviidual Differences, 25, 167-177.

Schutz, B. (1978). General Relativity. Igarss 2014. https://doi.org/10.1007/s13398-014-0173-7.2

Seligman, M. E. P. E. P. (2010). Flourish: Positive Psychology and Positive Interventions. The Tanner Lectures on Human Values, 231-242.

Thackray. (2017). Thackray Newsletter., 11(1), 1-11. Retrieved from www. alphamountain. com.

Veenhoven, R. (2015). Social conditions for human happiness: A review of research. International Journal of Psychology: Journal International de Psychologie, 50(5), 379-91. https://doi.org/10.1002/ijop.12161

Wongpakaran, T., Wongpakaran, N., Tanchakvaranont, S., Bookkamana, P., Pinyopornpanish, M., Wannarit, K., Thongpibul, K. (2016). Depression and pain: Testing of serial multiple mediators. Neuropsychiatric Disease and Treatment, 12, 1849-1860.

https://doi.org/10.2147/NDT.S110383

Yogeesvaran. K. (2013). The malaysian well-being report 2013. Retrieved from www.planningmalaysia.org/index.php/pmj/article/download/219. 